\title{
Oridonin induces apoptosis in SW1990 pancreatic cancer cells via p53- and caspase-dependent induction of p38 MAPK
}

\author{
HE-QI BU ${ }^{1 *}$, DIAN-LEI LIU ${ }^{2 *}$, WEI-TIAN WEI ${ }^{3}$, LIANG CHEN $^{4}, \mathrm{HAI} \mathrm{HUANG}^{2},{\text { YE } \mathrm{LI}^{2} \text { and JUN-HUI CUI }}^{1}$ \\ ${ }^{1}$ Department of Anorectal Surgery, Tongde Hospital of Zhejiang Province; ${ }^{2}$ Department of Surgery, Hangzhou Hospital \\ of Traditional Chinese Medicine; ${ }^{3}$ Department of Oncological Surgery, Zhejiang Cancer Hospital, Hangzhou; \\ ${ }^{4}$ Department of Surgery, the Second Affiliated Hospital of Wenzhou Medical College, Wenzhou, P.R. China
}

Received September 20, 2013; Accepted November 14, 2013

DOI: $10.3892 / o r .2013 .2888$

\begin{abstract}
Oridonin, an active component isolated from Rabdosia rubescens, has been reported to exhibit antitumor effects. In the present study, we evaluated the antitumor activity and the mechanisms of action of oridonin in pancreatic cancer. Oridonin treatment significantly induced apoptotic cell death in SW1990 pancreatic cancer cells in a dose-dependent manner. Additionally, cell apoptosis was markedly inhibited by PFT $\alpha$ (pifithrin $\alpha$ ), a p53-specific inhibitor, which was applied to evaluate the function of $\mathrm{p} 53$, showing that $\mathrm{p} 53$ was responsible for the cytotoxity of oridonin. Moreover, oridonin increased the expression of p-p53 with a concomitant increase in p21 in the SW1990 cells. Following treatment with mitogen-activated protein kinase (MAPK) inhibitors, PD98059 (ERK inhibitor), SP600125 (JNK inhibitor) and SB203580 (p38 inhibitor), the cytotoxity of oridonin was not influenced by JNK (SP600125) and ERK (PD98059), but these effects were opposite to the cytotoxity of oridonin observed with SP203580 treatment. These findings confirmed that orodonin-induced apoptosis was p38-dependent, but JNK- and ERK-independent. Furthermore, the activation of the $\mathrm{p} 38$ kinase promoted the activation of p53 and its downstream target p21, and further caused caspase- 9 and -3 activation, as demonstrated by evidence showing that the p38 inhibitor SB203580 not only blocked the phosphorylation of p38 but also reduced the activation of p53, p21 and caspase-9 and -3. Collectively, these results suggest that p53-dependent and caspase-dependent induction of p38 MAPK directly participates in apoptosis induced by oridonin.
\end{abstract}

Correspondence to: Professor Jun-Hui Cui, Department of Anorectal Surgery, Tongde Hospital of Zhejiang Province, No. 234 Gu-Cui Road, Hangzhou, Zhejiang 310012, P.R. China

E-mail: buheqi@163.com

*Contributed equally

Key words: oridonin, pancreatic cancer, p38, p53, caspases, apoptosis

\section{Introduction}

Pancreatic cancer is the fourth most common cause of cancerrelated mortality in the western world, with an estimated 35,000 deaths in 2009 in the United States (1). Less than $20 \%$ of pancreatic cancer patients are diagnosed with resectable and potentially curable disease, whereas most patients have advanced disease at the time of diagnosis and hence a dismal prognosis (2). This poor prognosis has been related to the difficulty of detection at the early stages of development, resulting in advanced disease at the time of presentation of first symptoms. With regard to patients with pancreatic cancer, for all stages, the 1-year survival rate is $23 \%$ and the 5 -year overall survival rate from diagnosis is $4 \%$. Median survival for patients with locally advanced disease is 9-12 months, and for patients with metastatic disease, the median survival is 3-6 months. The 5-year survival after curative resection is only $15-25 \%$ (3). In recent years, few agents have demonstrated significant benefit for patients with metastatic disease. Thus, effective new cytotoxic chemotherapy is needed for these diseases.

Oridonin, an ent-kaurane diterpenoid isolated from Rabdosia rubescens, is an important traditional Chinese herbal remedy, which has multiple biological activities, such as anti-inflammatory, antibacterial and antitumor effects (4). Existing research has confirmed that oridonin confers an inhibitive effect on the development of various types of cancers, and is a potential, effective, low-toxic antitumor medicine (5-13). However, mechanisms underlying the antitumor activity of oridonin and whether or not oridonin has anti-pancreatic cancer activity remain largely unknown.

In the present study, we investigated the involvement of MAPK signaling pathways in the anticancer effects of oridonin in pancreatic cancer cells, and we demonstrated that the MAPK pathway participated in oridonin-induced pancreatic cancer cell apoptosis. Importantly, a p38 inhibitor but neither an ERK inhibitor nor a JNK inhibitor, blocked the phosphorylation of $\mathrm{p} 38$ and also reduced the activation of p53, p21 and caspase-9 and -3. Taken together, the p38-MAPK pathway is required in oridonin-induced pancreatic cancer cell apoptosis, and which is dependent on its downstream target p53 and caspase activation. 


\section{Materials and methods}

Chemicals and reagents. Oridonin was obtained from the Beijing Institute of Biological Products (Beijing, China). The purity of the oridonin was measured by HPLC and determined to be $99.4 \%$. Oridonin was dissolved in dimethyl sulfoxide (DMSO) to make a stock solution at a $10 \mathrm{mmol} / \mathrm{l}$ concentration and stored at $-20^{\circ} \mathrm{C}$. The DMSO concentration was kept below $0.1 \%$ in all the cell cultures and did not exert any detectable effect on cell growth or cell death. Fetal bovine serum (FBS), trypsin containing EDTA, Roswell Park Memorial Institute-1640 (RPMI-1640) and the Cell Counting Kit-8 (CCK-8) were obtained from Gibco (USA). Annexin V-FITC/PI Apoptosis Detection Kit I was obtained from BD Bioscience. The p53 inhibitor pifithrin $\alpha$ (PFT $\alpha$ ) was obtained from Biomol International (Plymouth Meeting, PA, USA). The ERK inhibitor PD98059, p38 inhibitor SB203580 and JNK inhibitor SP600125 were obtained from Calbiochem (San Diego, CA, USA). RNA extraction kit was purchased from Life Technologies Co., cDNA First Strand Synthesis kit was purchased from Fermentas, and 2X Taq PCR Master Mix was purchased from Tiangen. Ribonuclease A (RNase A), propidium iodide (PI), Hoechst 33258 and DMSO were obtained from Sigma. Antibodies against p53, phospho-p53, p38, phospho-p38,p21, caspase-9, caspase-3, $\beta$-actin and horseradish peroxidase (HRP)-conjugated secondary antibodies (goat antirabbit and goat anti-mouse) were purchased from Sigma.

Cell culture. The SW1990 pancreatic cancer cell line was obtained from the American Type Culture Collection (ATCC; Manassas, VA, USA). The human normal pancreas cell line HPDE6c7 was obtained from Guangzhou Jennio Biotech Co., Ltd. (Guangzhou, China). The cells were cultured in RPMI1640 supplemented with $10 \% \mathrm{FBS}, 100 \mathrm{U} / \mathrm{ml}$ penicillin, and $100 \mu \mathrm{g} / \mathrm{ml}$ streptomycin. Cells were maintained at $37^{\circ} \mathrm{C}$ in a humidified atmosphere of $5 \% \mathrm{CO}_{2}$. The medium was changed every second to third day, and cells were subcultured when confluency reached $70-80 \%$ by $0.25 \%$ trypsin at $37^{\circ} \mathrm{C}$.

Cytotoxicity assay. The cytotoxic effect of oridonin on SW1990 and HPDE6c7 cells was determined using the CCK-8. Briefly, the logarithmic phase cells were plated in 96-well culture plates $\left(5 \times 10^{3}\right.$ cells per well). After $24 \mathrm{~h}$ of incubation, the cells were treated with vehicle alone ( $0.1 \%$ DMSO) and various concentrations $(10,20,40,80,160 \mu \mathrm{M})$ of oridonin, followed by a 48 -h cell culture. In addition, in experiments to determine the effects of MAPK inhibitors (PD98059, SP600125 and SB203580) and the p53 inhibitor (PFT $\alpha$ ) on cell cytotoxicity, cells were pretreated with the inhibitors for $1 \mathrm{~h}$ at the given concentrations and then incubated with the specified concentration of oridonin for $48 \mathrm{~h}$. Each group had 6 wells, and CCK-8 (100 $\mu \mathrm{l})$ was added to each well $1 \mathrm{~h}$ before the end of incubation. The absorbance at $450 \mathrm{~nm}$ was read using Bio-Tek, ELX800. Experiments were repeated three times. The cytotoxic effect was expressed as a relative percentage of cell death calculated as follows: Cell death $(\%)=$ 1 - (dosing absorbance - blank absorbance)/(control absorbance - blank absorbance) x100.

Observation of apoptotic cell morphology. Apoptotic morphology was monitored in DAPI- and Hoechst 33258- stained cells. Cells $\left(4 \times 10^{5}\right)$ were grown for $48 \mathrm{~h}$ on coverslips on a 6-well plate in the presence or absence of $40 \mu \mathrm{M}$ oridonin. After $48 \mathrm{~h}$ of incubation, the coverslips were carefully washed with PBS, fixed with $4 \%$ paraformaldehyde at room temperature for $30 \mathrm{~min}$ and respectively incubated with $10 \mu \mathrm{g} / \mathrm{ml}$ DAPI and $10 \mu \mathrm{g} / \mathrm{ml}$ Hoechst 33258 at room temperature for $30 \mathrm{~min}$. Thereafter, cells were again washed and resuspended in PBS for morphological observation under a fluorescence microscope (Nikon, Japan).

Flow cytometric analysis of cell cycle distribution and apoptosis. Analysis of cell cycle distribution was measured by staining DNA with PI according to the manufacturer's protocol. SW1990 cells were seeded into 6-well plates at a density of $\sim 5 \times 10^{5}$ cells per well, cultured overnight, and then treated with various concentrations of oridonin $(20,40,80 \mu \mathrm{M})$. Control cells were treated with $0.1 \%$ DMSO only. Cells were incubated for $48 \mathrm{~h}$. Both detached and adherent cells were collected and centrifuged at $1000 \mathrm{xg}$ for $5 \mathrm{~min}$ at $4^{\circ} \mathrm{C}$. Pellets were rinsed with ice-cold phosphate-buffered saline (PBS) and fixed with $70 \%$ ethanol for $24 \mathrm{~h}$ at $4^{\circ} \mathrm{C}$. Cells were then stained with staining buffer (PBS containing $50 \mu \mathrm{g} / \mathrm{ml}$ of PI, $10 \mu \mathrm{g} / \mathrm{ml}$ RNase A, $0.1 \%$ sodium citrate and $0.1 \%$ Triton X-100) for at least $15 \mathrm{~min}$ at $37^{\circ} \mathrm{C}$ in the dark. Samples were analyzed by a flow cytometer (BD Bioscience).

Apoptosis in SW1990 cells was evaluated using Annexin V-FITC Apoptosis Detection Kit I, which was performed according to the manufacturer's protocol. The SW1990 cells were cultured as above, then treated with various concentrations of oridonin $(20,40,80 \mu \mathrm{M})$. Control cells were treated with $0.1 \%$ DMSO only. Cells were collected after a 48 -h incubation, washed with PBS, resuspended in binding buffer, and incubated with FITC and PI staining solution following the manufacturer's instructions. Samples of 10,000 stained cells were analyzed by flow cytometry (BD Bioscience).

Western blot analysis. SW1990 cells were treated with the desired concentration of oridonin in the absence or presence of inhibitors for $48 \mathrm{~h}$. Both adherent and floating cells were collected, and then western blot analysis was performed. The cells were washed with ice-cold PBS, and lysed on ice for $40 \mathrm{~min}$ in a solution containing $50 \mathrm{mM}$ Tris, $1 \%$ Triton X-100, $0.1 \% \mathrm{SDS}, 150 \mathrm{mM} \mathrm{NaCl}, 2 \mathrm{mM} \mathrm{Na}_{3} \mathrm{VO}_{4}, 2 \mathrm{mM}$ EGTA, $12 \mathrm{mM}$ $\beta$-glycerolphosphate, $10 \mathrm{mM} \mathrm{NaF}, 16 \mu \mathrm{g} / \mathrm{ml}$ benzamidine hydrochloride, $10 \mu \mathrm{g} / \mathrm{ml}$ phenanthroline, $10 \mu \mathrm{g} / \mathrm{ml}$ aprotinin, $10 \mu \mathrm{g} / \mathrm{ml}$ leupeptin, $10 \mu \mathrm{g} / \mathrm{ml}$ pepstatin, and $1 \mathrm{mM}$ phenylmethylsulfonyl fluoride, and then lysed at $4^{\circ} \mathrm{C}$ for $60 \mathrm{~min}$. The cell lysate was centrifuged at $14,000 \mathrm{x}$ g for $15 \mathrm{~min}$, and the supernatant fraction was collected for western blotting. Protein content in the supernatant fraction was determined by bicinchoninic acid (BCA) assay kit (Sigma) according to the manufacturer's instructions. The protein lysates (20 $\mu \mathrm{g} / \mathrm{lane})$ were separated by electrophoresis on $12 \%$ SDS polyacrylamide gel and then transferred to a nitrocellulose membrane. After blocking for $1 \mathrm{~h}$ in $10 \%$ nonfat dry milk in Tris-buffered saline, the membrane was incubated with the desired primary antibody for $1 \mathrm{~h}$. The membrane was then treated with the appropriate peroxidase-conjugated secondary antibody, and the immunoreactive proteins were detected using an enhanced chemiluminescence kit (NEN Life Science Products, Boston, 


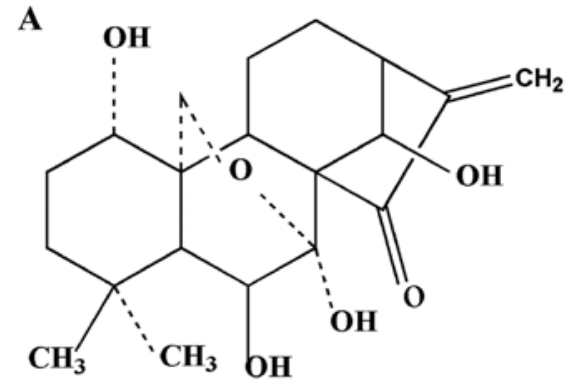

Chemical structure of oridonin

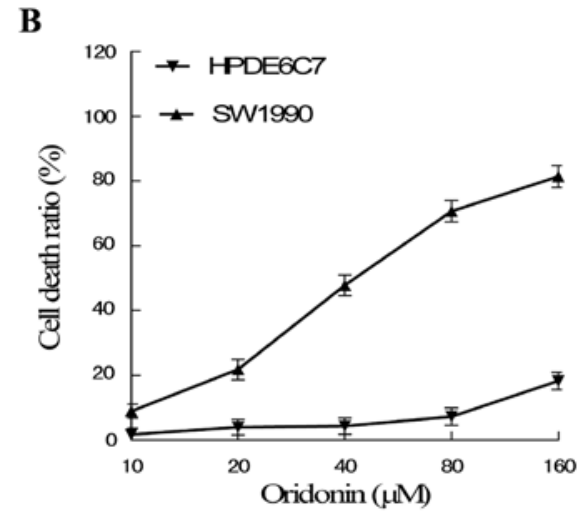

Figure 1. Cytotoxity of oridonin in pancreatic cancer SW1990 and HPDE6c7 cells. (A) Chemical structure of oridonin. (B) The SW1990 and HPDE6c7 cells were treated with various doses of oridonin for $48 \mathrm{~h}$. The cell death ratio was measured by CCK- 8 assay. The results are representative of three independent experiments. All data are presented as mean \pm SD.

Table I. Primer pairs used in the semi-quantitative polymerase chain reaction.

\begin{tabular}{llc}
\hline Genes & \multicolumn{1}{c}{$\begin{array}{c}\text { Primer pairs } \\
\left(5^{\prime} \rightarrow 3^{\prime}\right)\end{array}$} & $\begin{array}{c}\text { Product } \\
\text { size }(\mathrm{bp})\end{array}$ \\
\hline p38 & & \\
Sense & CGGAGTGGCATGAAGCTGTAG & 346 \\
Antisense & CCCTAGGAAACCAACACAGCA & \\
p53 & & \\
Sense & TCTGGGACAGCCAAGTCTGT & 435 \\
Antisense & GGAGTCTTCCAGT-GTGATGA & \\
p21 & & 248 \\
Sense & AAACGGGAACCAGGACAC & \\
Antisense & AGCAGCGGAACAAGGAGT & \\
Caspase-9 & & 325 \\
Sense & GGTTCTGGAGGATTTGGTGA & \\
Antisense & GACAGCCGTGAGAGAGAATGA & \\
Caspase-3 & & \\
Sense & AGCAAACCTCAGGGAAACATT & 309 \\
Antisense & GTCTCAATGCCACAGTCCAGT & \\
GAPDH & & \\
Sense & AACGGATTTGGTCGTATTGGG & 216 \\
Antisense & TCGCTCCTGGAAGATGGTGAT & \\
\hline
\end{tabular}

MA, USA) according to the manufacturer's instructions. Each membrane was stripped and reprobed with antibodies against actin to correct for differences in protein loading. Quantitative data were expressed as mean \pm SD of the relative levels of the objective protein and control $\beta$-actin of each group of cells from three independent experiments.

Semi-quantitative RT-PCR assay. SW1990 cells were treated with the desired concentration of oridonin in the absence or presence of inhibitors for $48 \mathrm{~h}$, and both adherent and floating cells were collected. Subsequently, total cellular RNAs were isolated from the cells using TRIzol reagent. The content of
RNA was measured using a UV spectrophotometer under $260 \mathrm{~nm}$. cDNA was synthesized with $1 \mu \mathrm{g}$ of total RNA and oligo(dT) primer according to the manufacturer's instructions. PCR amplification conditions were: p38, $94^{\circ} \mathrm{C}$ for $60 \mathrm{sec}$, $61.8^{\circ} \mathrm{C}$ for $60 \mathrm{sec}, 72^{\circ} \mathrm{C}$ for $60 \mathrm{sec}, 35$ cycles; $\mathrm{p} 53,94^{\circ} \mathrm{C}$ for $45 \mathrm{sec}, 51.9^{\circ} \mathrm{C}$ for $1 \mathrm{~min}, 72^{\circ} \mathrm{C}$ for $90 \mathrm{sec}, 35$ cycles; $\mathrm{p} 21,94^{\circ} \mathrm{C}$ for $30 \mathrm{sec}, 54^{\circ} \mathrm{C}$ for $30 \mathrm{sec}, 72^{\circ} \mathrm{C}$ for $1 \mathrm{~min}, 30$ cycles; caspase- 9 , $94^{\circ} \mathrm{C}$ for $30 \mathrm{sec}, 56^{\circ} \mathrm{C}$ for $30 \mathrm{sec}, 72^{\circ} \mathrm{C}$ for $30 \mathrm{sec}, 35 \mathrm{cycles}$; caspase- $3,94^{\circ} \mathrm{C}$ for $30 \mathrm{sec}, 57^{\circ} \mathrm{C}$ for $30 \mathrm{sec}, 72^{\circ} \mathrm{C}$ for $30 \mathrm{sec}$, 35 cycles; GAPDH, $94^{\circ} \mathrm{C}$ for $30 \mathrm{sec}, 54^{\circ} \mathrm{C}$ for $30 \mathrm{sec}, 72^{\circ} \mathrm{C}$ for $20 \mathrm{sec}, 25$ cycles. GAPDH was used as an internal control. The primer pairs used for the amplification are listed in Table I. Five microliters of the product were added to the $1 \%$ agarose gel electrophoresis and images of the results were captured.

Statistical analysis. All results were confirmed in at least three separate experiments. Statistical analysis was performed using SPSS 17.0. Significant differences were determined by ANOVA, followed by the Student's t-test for statistical analysis. The data were expressed as mean \pm SD. A P-value $<0.05$ was considered to indicate a statistically significant difference.

\section{Results}

Cytotoxic effects of oridonin on SW1990 and HPDE6c7 cells. To detect the cytotoxic effects of oridonin on SW1990 and HPDE6c7 cells, the cells were cultured with 10, 20, 40, 80 and $160 \mu \mathrm{M}$ oridonin for $48 \mathrm{~h}$. The results showed that oridonin induced SW1990 cell death in a dose-dependent manner; the effects at concentrations of $20-80 \mu \mathrm{M}$ oridonin were apparent. In addition, oridonin only exhibited a low cytotoxic effect on the human normal pancreas cell line HPDE6c7 at below a concentration of $80 \mu \mathrm{M}$ oridonin (Fig. 1).

Oridonin induces apoptotic cell death in SW1990 cells. To determine whether cell death induced by oridonin in SW1990 cells was caused by apoptosis, SW1990 cells were treated with $40 \mu \mathrm{M}$ oridonin for $48 \mathrm{~h}$, and the morphological changes were examined with DAPI and Hoechst 33258 staining. As shown in Fig. 2, the nuclei of cells were round and homogeneously stained in the control group; however, following treatment 

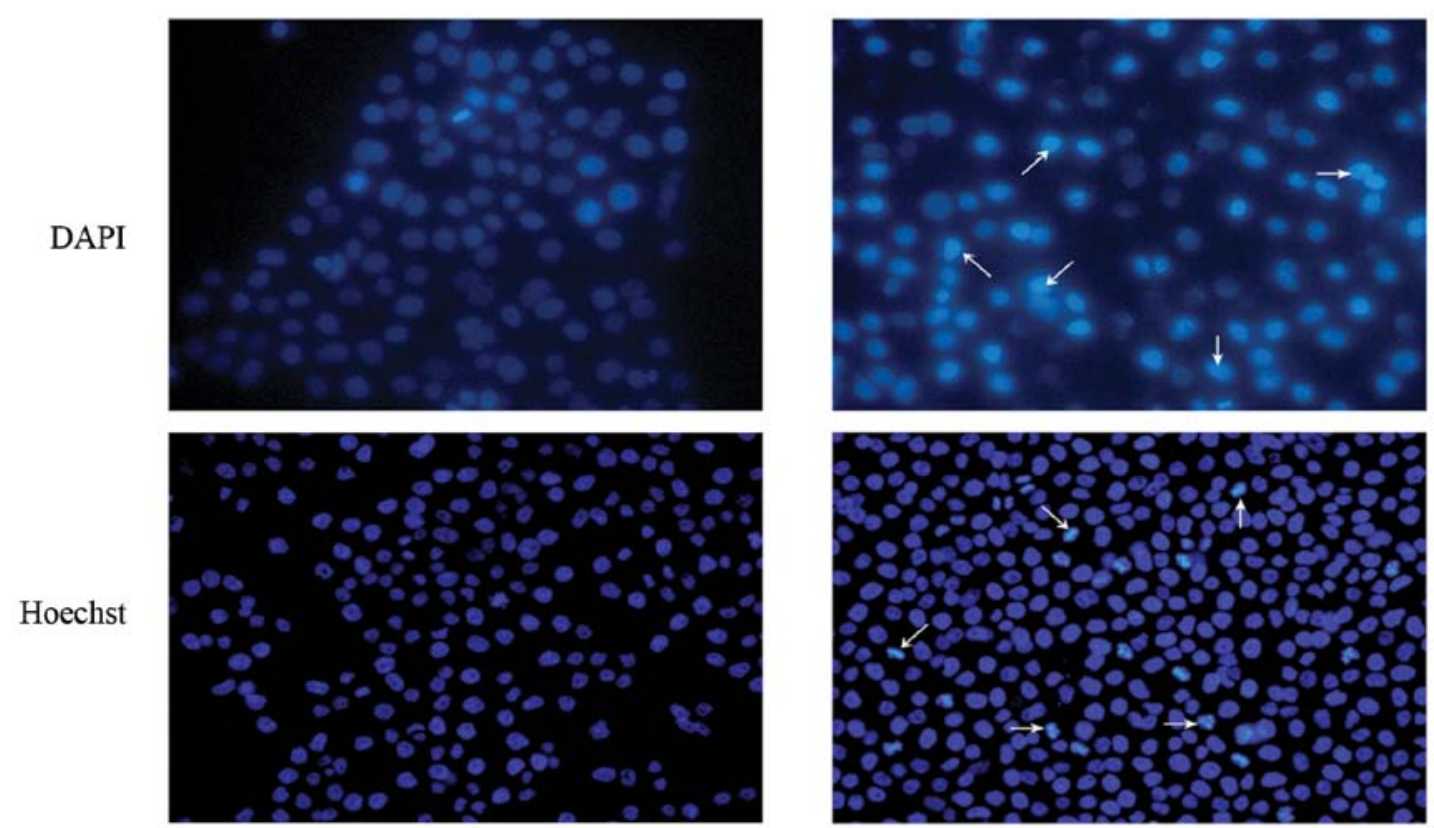

Control

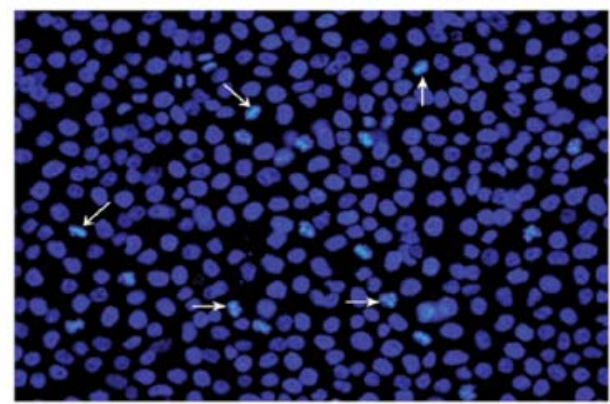

Oridonin $(40 \mu \mathrm{M})$

Figure 2. Morphological apoptotic changes in the SW1990 cells following oridonin treatment. The SW1990 cells were treated with $40 \mu \mathrm{M}$ oridonin or vehicle for $48 \mathrm{~h}$, and cellular morphological changes were observed by means of DAPI (x400) or Hoechst 33258 (x400) staining and visualized by fluorescence microscopy. Representative DAPI-stained and Hoechst 33258-stained nuclei of cells are shown. Typical apoptotic changes in the nucleus (chromatin condensation, nuclear fragmentation, appearance of apoptotic bodies) are indicated by arrows.

A

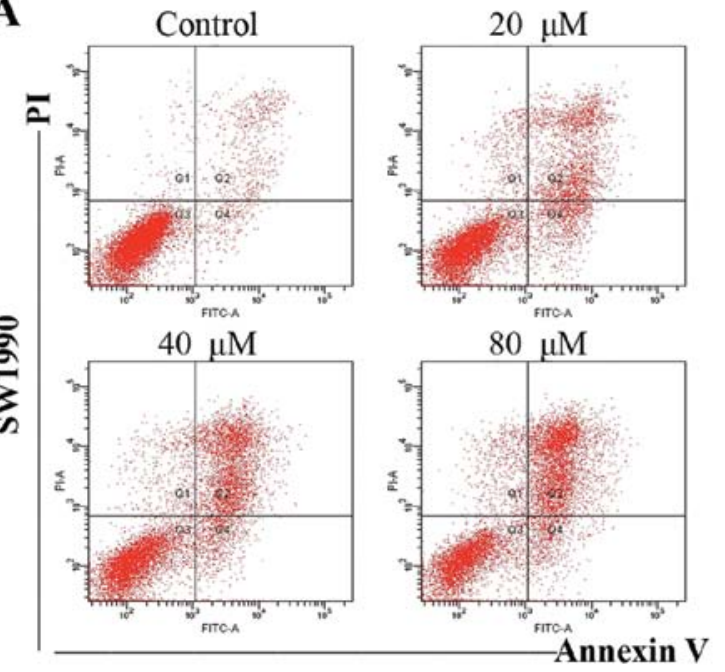

B

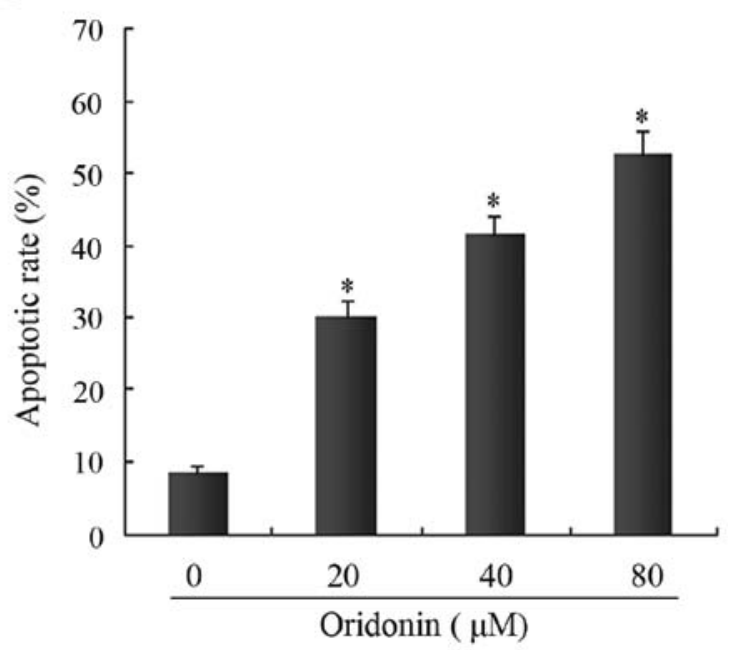

Figure 3. Oridonin induces apoptotic cell death in SW1990 cells. (A) The SW1990 cells were treated with oridonin (20,40, $80 \mu \mathrm{M})$ or vehicle for $48 \mathrm{~h}$, and then stained with Annexin V-FITC/PI and analyzed by flow cytometry. Results are representative of three independent experiments. (B) The percentage of apoptotic cells is presented as the mean \pm SD of three independent experiments. " $\mathrm{P}<0.05$ vs. the control.

with $40 \mu \mathrm{M}$ oridonin, the cells displayed marked blebbing of the nuclei and apoptotic bodies.

To further determine the features of SW1990 cell death, flow cytometric analysis was performed using Annexin V-FITC/ PI-stained SW1990 cells. In the control group, the apoptotic cell ratio was $\sim 8.5 \pm 0.7 \%$. In the presence of oridonin at 20 , 40 and $80 \mu \mathrm{M}$, the numbers of apoptotic cells increased to $31.2 \pm 2.2,41.4 \pm 2.9$ and $50.5 \pm 3.4 \%$ at $48 \mathrm{~h}$, respectively. There were significant differences in the apoptotic ratio of cells between the oridonin-treated groups and the control group
$(\mathrm{P}<0.05)$ (Fig. 3). These results demonstrated that oridonin treatment induced apoptosis in a dose-dependent manner; one of the causes of SW1990 cell death induced by oridonin was apoptosis.

To further confirm the finding that oridonin induced SW1990 apoptotic cell death, the DNA contents of SW1990 pancreatic cancer cells treated with $0,20,40$ and $80 \mu \mathrm{M}$ oridonin for $48 \mathrm{~h}$ were analyzed using a flow cytometer. As shown in Fig. 4, oridonin increased the ratio of cells in the G0/G1 phase and decreased those in the S and G2/M phase 
A
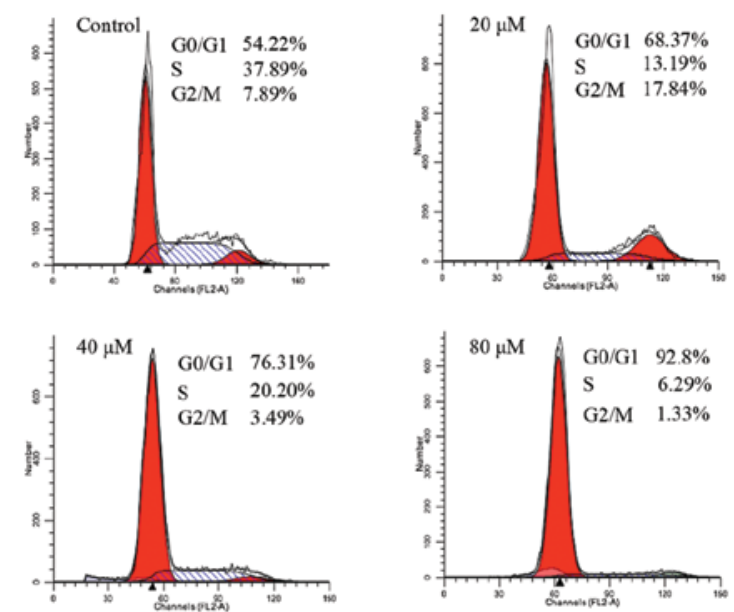

B

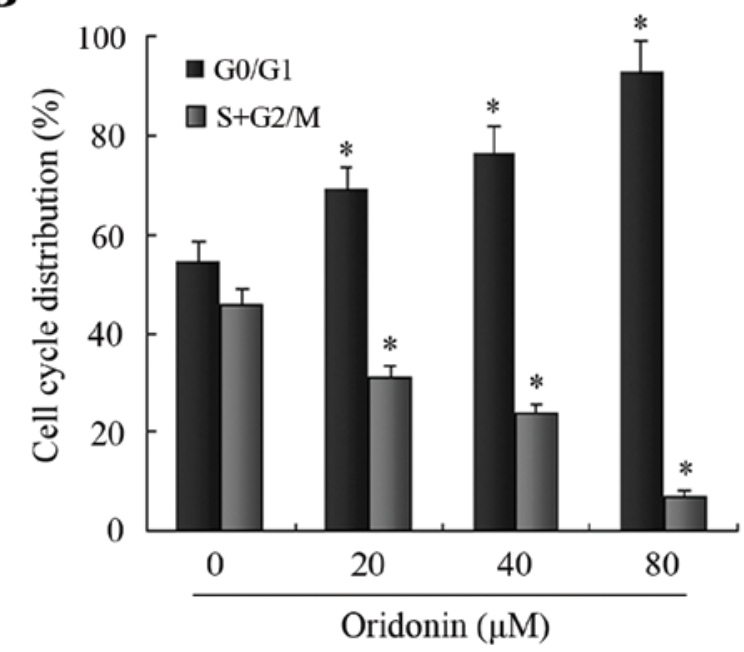

Figure 4. Effects of oridonin on cell cycle distribution of SW1990 cells. Cells were treated with oridonin $(20,40,80 \mu \mathrm{M})$ or vehicle for $48 \mathrm{~h}$ and stained with PI. Cellular DNA contents were assessed by flow cytometry. (A) Results are representative of three independent experiments. (B) The percentages of G0/G1, S and $\mathrm{G} 2 / \mathrm{M}$ phase cells are shown as indicated and presented as the mean $\pm \mathrm{SD}$ of three independent experiments. * $\mathrm{P}<0.05$ vs. the control.

A

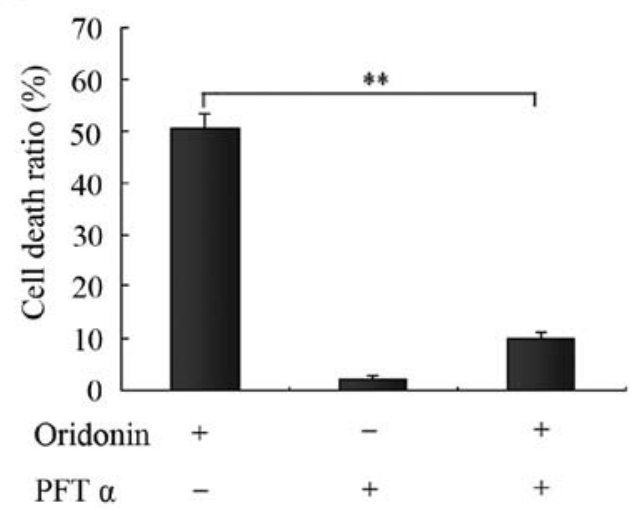

B

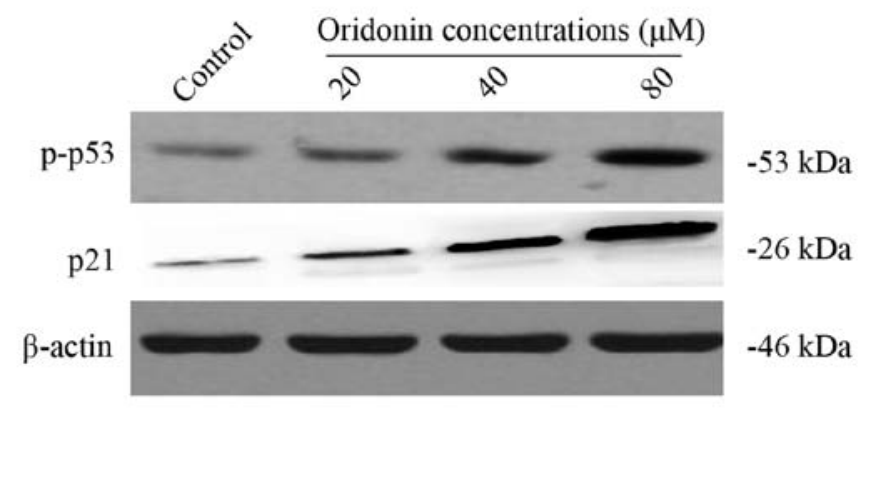

Figure 5. The role of p53 and p21 in oridonin-induced SW1990 cell apoptosis. (A) The cells were pretreated with $15 \mu \mathrm{M}$ PFT $\alpha$ for $1 \mathrm{~h}$ and then cultured with $40 \mu \mathrm{M}$ oridonin for $48 \mathrm{~h}$. Cell death ratio was measured by CCK- 8 assay. The results are representative of three independent experiments. All data are presented as means \pm SD. ${ }^{* *} \mathrm{P}<0.05$ vs. the control. (B) The cells were treated with oridonin $(20,40,80 \mu \mathrm{M})$ or vehicle for $48 \mathrm{~h}$; and cell lysates were separated by $12 \%$ SDS-PAGE electrophoresis, and phospho-p53 and p21 protein expression was detected by western blot analysis.

in a dose-dependent manner, and thus caused a significant inhibition of cell cycle progression in SW1990 cells. There were significant differences in the ratio of cells in the G0/ G1 phase and S plus the G2/M phases between the oridonintreated groups and the control group $(\mathrm{P}<0.05)$. These results suggested that oridonin treatment caused SW1990 cell death by inducing apoptosis associated with cell cycle arrest.

p53 and its downstream protein p21 are involved in oridonininduced SW1990 cell apoptosis. The tumor-suppressor gene product p53 has been reported to mediate apoptosis in many experimental systems and is capable of transcriptionally activating p21, which is responsible for its tumor suppressive function (14). In the present study, the p53-specific inhibitor PFT $\alpha$ was applied to evaluate the function of p53 in oridonin-induced SW1990 cell apoptosis. After incubation of SW1990 cells with $40 \mu \mathrm{M}$ oridonin for $48 \mathrm{~h}, 15 \mu \mathrm{M}$ PFT $\alpha$ significantly reduced apoptosis from 50.5 to $9.8 \%$ (Fig. 5A). To further confirm this result, western blot analysis was carried out to determine the p53 and phospho-p53 expression. After treatment of SW1990 cells with various concentrations of oridonin $(0,20,40,80 \mu \mathrm{M})$ for $48 \mathrm{~h}$, the expression of $\mathrm{p} 53$ did not change (data not shown), while the level of phosphop53 was markedly increased with increasing concentrations of oridonin. Moreover, we further analyzed the expression of p21, a downstream protein of p53, using western blotting as above. Unexpectedly, expression of p21 was also dramatically increased in a dose-dependent manner. These findings revealed that $\mathrm{p} 53$ and its downstream protein $\mathrm{p} 21$ participated in the oridonin-induced apoptosis (Fig. 5B).

Effects of inhibitors of ERK, p38, and JNK on oridonintreated SW1990 cells. To determine whether the MAPK family was involved in the oridonin-induced SW1990 pancreatic cancer cell apoptosis, $10 \mu \mathrm{M}$ ERK inhibitor PD98059, $10 \mu \mathrm{M}$ p38-MAPK inhibitor SB203580, and $10 \mu \mathrm{M}$ JNK 
A

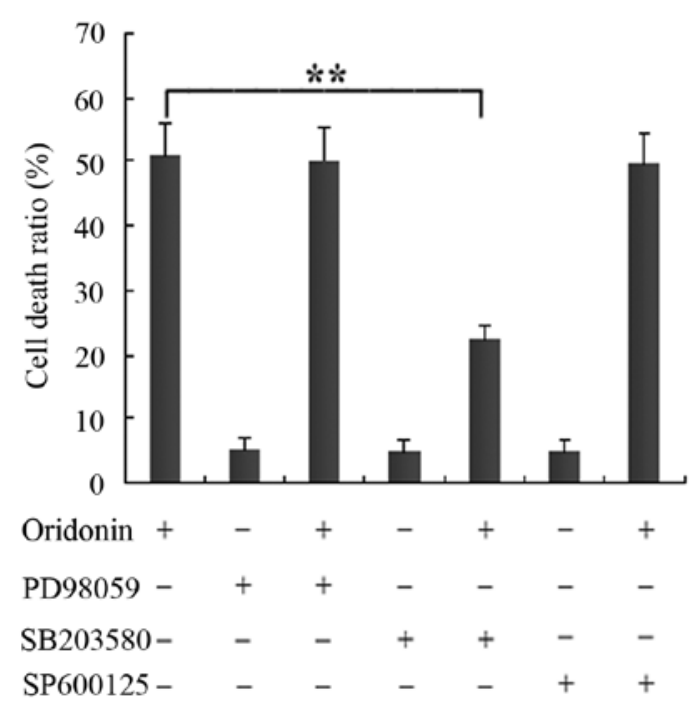

B
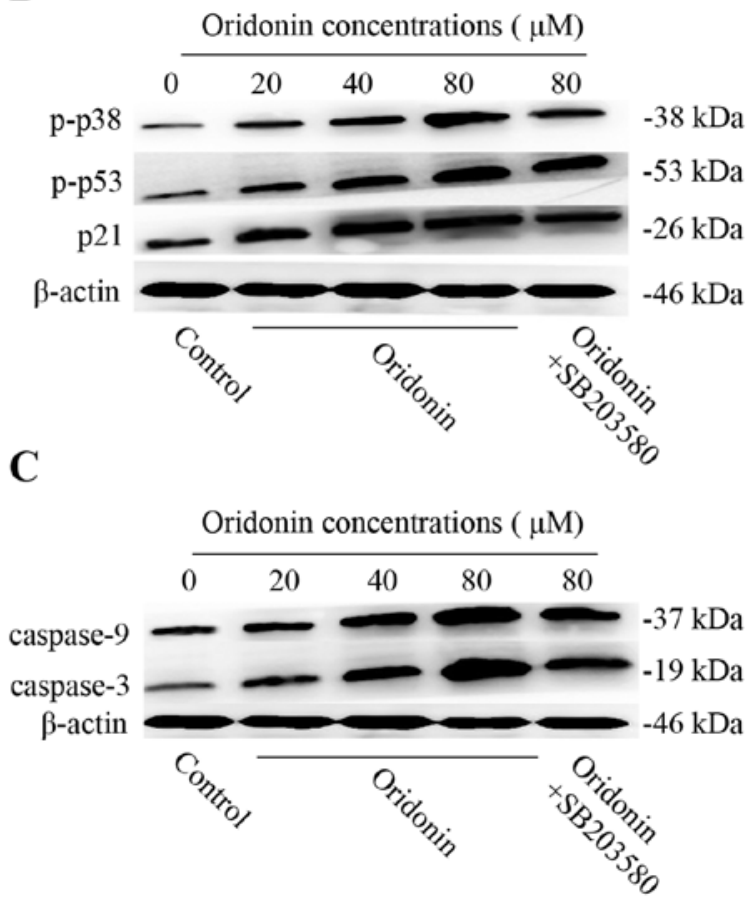

Figure 6. p38 is activated, which further promotes the the activation of p53, p21, caspase-9 and caspase-3 in SW1990 cells. (A) The SW1990 cells were pretreated with $10 \mu \mathrm{M} \mathrm{SB} 203580,10 \mu \mathrm{M} \mathrm{SP600125,} \mathrm{or} 10 \mu \mathrm{M}$ PD98059 for $1 \mathrm{~h}$ and then cultured with $40 \mu \mathrm{M}$ oridonin for $48 \mathrm{~h}$. Cell death ratio was measured by CCK- 8 assay. The results are representative of three independent experiments. All data are presented as means $\pm \mathrm{SD}$. ${ }^{* *} \mathrm{P}<0.05$ vs. the control. (B and C) The SW1990 cells were treated with oridonin $(20,40,80 \mu \mathrm{M})$ or vehicle for $48 \mathrm{~h}$ in the absence or presence of $10 \mu \mathrm{M}$ SB203580; and cell lysates were separated by $12 \%$ SDS-PAGE electrophoresis, and the protein expression of phospho-p38 and phospho-p53, p21, caspase-9 and caspase-3 was detected by western blot analysis. The results are representative of three independent experiments. All data are presented as means \pm SD.

inhibitor SP600125 were administered. SW1990 cells were pretreated with $10 \mu \mathrm{M}$ PD98059, $10 \mu \mathrm{M} \mathrm{SB} 203580$, and $10 \mu \mathrm{M}$ SP600125 for $60 \mathrm{~min}$, and then cultured with $40 \mu \mathrm{M}$ oridonin for $48 \mathrm{~h}$. The results showed that the stimulatory effect of oridonin was unaffected in the presence of PD98059 or SP600125. In contrast, $10 \mu \mathrm{M}$ of the p38 inhibitor SB203580 partially inhibited the cell death from 51.3 to $22.4 \%$ (Fig. 6A). On the basis of these results, western blot analysis was carried out. After treatment of SW1990 cells with various concentrations of oridonin $(0,20,40,80 \mu \mathrm{M})$ for $48 \mathrm{~h}$, the level of phospho-p38 increased with increasing concentrations of oridonin. However, in the presence of $10 \mu \mathrm{M}$ SB203580, SB203580 almost thoroughly reversed the phosphorylation of p38 (Fig. 6B), indicating that the activation of p38 was also involved in oridonin-induced SW1990 cell apoptosis.

Activation of p38 kinase in oridonin-treated SW1990 cells contributes to further activation of p53 and p21. Previously, it has been reported that p38 kinase can phosphorylate $\mathrm{N}$-terminal serine residues of $\mathrm{p} 53$, thereby triggering the proapoptotic transactivating function of $\mathrm{p} 53$, which in turn leads to apoptosis (15). According to this research, western blot analysis was performed to examine the effects of SB203580 on the level of phospho-p53 and p21. As shown in Fig. 6B, when SW1990 cells were treated with various concentrations of oridonin $(0,20,40,80 \mu \mathrm{M})$ for $48 \mathrm{~h}$, the enhanced phosphop53 expression at $80 \mu \mathrm{M}$ of ordonin was significantly reduced by $10 \mu \mathrm{M}$ SB203580. Concomittantly, p21, the downstream protein of $\mathrm{p} 53$, diplayed a similar trend. These observations indicated that oridonin-induced SW1990 cell apoptosis did not require ERK and JNK activation; however, it was dependent on p38-MAPK activity, which contributed to further activation of $\mathrm{p} 53$ and its downstream protein $\mathrm{p} 21$.

Involvement of the caspase pathway in the oridonin-induced SW1990 cell apoptosis. It is well known that caspases are required for apoptosis. However, whether the caspase pathway was initiated by p38 MAPK was unclear. We further examined the protein expression of caspase-9, caspase-3 and the effects of SB203580 on the expression of caspase- 9 and -3. The expression of caspase-9 and caspase-3 in SW1990 cells following the treatment with various concentrations of oridonin $(0,20,40,80 \mu \mathrm{M})$ in the absence or presence of SB203580 for $48 \mathrm{~h}$ was examined by western blot analysis. The results showed that the expression of caspase- 9 and -3 was significantly increased in a dose-dependent manner. However, in the presence of $10 \mu \mathrm{M}$ SB203580, the levels were unexpectedly decreased (Fig. 6C), indicating that oridonin induced SW1990 apoptosis by p38 MAPK, which was dependent on the caspase pathway.

mRNA expression of 38 , p53,p21, caspase-9 and -3 in SW1990 cells. To further clarify whether the possible mechanism was related to p38, p53, p21 caspase-9 and caspase-3 genes, RT-PCR was carried out to detect the mRNA expression in the SW1990 pancreatic cancer cell line. After SW1990 cells were exposed to various concentrations of oridonin $(0,20,40,80 \mu \mathrm{M})$ for $48 \mathrm{~h}$, the expression of p38, p53, p21, caspase- 9 and caspase- 3 


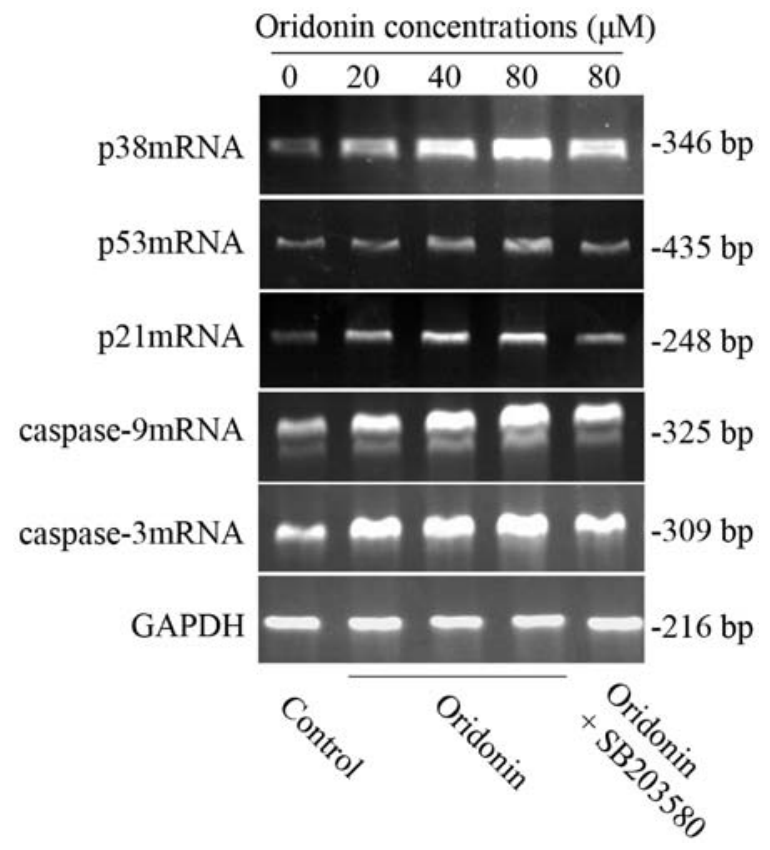

Figure 7. Effects of oridonin on the mRNA expression of p38,p53,p21, caspase-9 and caspase-3 in SW1990 cells. The cells were cultured with oridonin $(20,40$, $80 \mu \mathrm{M}$ ) or vehicle for $48 \mathrm{~h}$ in the absence or presence of $10 \mu \mathrm{M} \mathrm{SB} 203580$; the mRNA expression of p38, p53, P21, caspase- 9 and caspase-3 was analyzed by RT-PCR. The results are representative of three independent experiments. All data are presented as mean $\pm \mathrm{SD}$.

mRNA all increased in a dose-dependent manner. However, in the presence of $10 \mu \mathrm{M}$ SB203580, their mRNA expression was similarly reduced (Fig. 7) as well as the protein expression. The results further confirmed our above conclusion.

\section{Discussion}

The aim of the present study was to determine whether oridonin has potential in the treatment of pancreatic cancer, one of the most lethal cancers. In the SW1990 pancreatic cancer cell line, we found that oridonin was able to induce cell death in a dosedependent manner, and this in vitro effect was through cell cycle arrest in the G0/G1 phase and induction of apoptosis. More importantly, we found that p38, not ERK or JNK, was activated, and the expression levels of p53, p21 and caspase-9 and -3 were upregulated, which were reduced in the presence of SB203580 in oridonin-induced SW1990 cell apoptosis. The activation of p38 MAPK was involved in the induction of apoptosis in SW1990 pancreatic cancer cells and this may be one of the mechanisms. These results provide strong evidence to support the notion that oridonin has strong activity against pancreatic cancer. To the best of our knowledge, this is the first in vitro study concerning the chemotherapeutic effects of oridonin against SW1990 pancreatic cancer cells.

The $\mathrm{p} 53$ pathway is targeted for inactivation in most human cancers either directly or indirectly, highlighting its critical function as a tumor-suppressor gene (16). The p53 tumor suppressor is essential for maintaining genomic stability in mammals. p53 function is usually switched off; although when cells are subjected to stress signals such as hypoxia, radiation, or chemotherapeutic drugs, p53 is activated, and its ubiquitindependent degradation is blocked leading to an accumulation of active p53 transcription factor (17). Upon activation, p53 mediates a growth-suppressive effect on cells by blocking the cell cycle or it can lead cells to undergo programmed cell death primarily by binding to particular DNA sequences and activating transcription of specific genes (18). In addition, the tumor suppressor p53 is implicated in induction of growth arrest. Following DNA damage, p53 increases the transcription of $\mathrm{p} 21$, which plays a pivotal role in controlling cell-cycle progression by binding directly to $\mathrm{CDK} /$ cyclin complexes (19). The expression of cyclin-dependent kinase inhibitor p21 has been implicated in chemotherapy-induced cell cycle arrest in numerous human cancers $(20,21)$. In our study, we confirmed that oridonin is capable of activating p53 and p21 in pancreatic cancer cells. CCK-8, flow cytometric analysis and western blot analysis assay showed that the activation of p53 was accompanied by the upregulation of p21, which was able to arrest the cell cycle in the G0/G1 phase, thus transmitting apoptotic signals in oridonin-treated SW1990 cells, as verified by the evidence that the ratio of cell death was effectively suppressed by PFT $\alpha$. This is in agreement with previous findings that the p53 inhibitor pifithrin was able to significantly reduce oridonin-induced apoptosis in HepG2 cells (7).

Mitogen-activated protein kinases (MAPKs) are serine/ threonine kinases that mediate intracellular signaling associated with a variety of cellular activities including cell proliferation, differentiation, survival, death and transformation $(22,23)$. The three main members that integrate the MAPK family in mammalian cells are stress-activated protein kinase c-Jun NH2-terminal kinase (JNK), stress-activated protein kinase 2 (SAPK2, p38), and the extracellular signal-regulated protein kinases (ERK1/2, p44/p42). The p38 signaling pathways are activated by proinflammatory (TNF- $\alpha$, IL- 6 or IL-1) or anti-inflammatory (EGF, TGF- $\beta$ ) cytokines, but also in response to cellular stresses such as genotoxic, osmotic, hypoxic or oxidative stress (24). Activation of p38 kinase has also been implicated in anticancer drug-induced apoptosis (25). Of note, in our study, pretreatment of SB203580 was effective in preventing oridonin-induced apoptosis, indicating that p38 was involved in this process. This is consistent with previous studies that the p38-MAPK pathway was involved in cell cycle regulation and/or apoptosis (26).

MAPKs have been shown to be responsive to different stress stimuli. Upon activation, p38 phosphorylates and regulates various transcription factors (including ATF-2, NF- $\kappa \mathrm{B}$, Elk-1, Max, Mac, p53 or Stat1) $(27,28)$ and other cell cycle and apoptotic mediators (e.g., p21, Cdc25A, Bcl-2) (29), but, of particular note, it has been demonstrated to phosphorylate the tumor suppressor p53, which can initiate the p53 response, leading to cell cycle arrest and apoptosis $(30,31)$. Previous studies have documented that activation of the p38-MAPK pathway may lead to p53-induced apoptosis (32). In the present study, we found that in response to oridonin treatment increased expression of p-p38 was accompanied by the upregulation of p-p53 and p21, suggesting that the activation of $\mathrm{p} 38$ further contributed to the activation of $\mathrm{p} 53$ and $\mathrm{p} 21$. This was further verified by the evidence that high levels of phospho-p53 and p21 were effectively inhibited by SB203580. This is consistent with a previous study which found that a p38 inhibitor was able to partially inhibit cell 
death and the activation of p53 in oridonin-treated HepG2 cells (7).

Caspases are a family of cysteine proteases, which play key roles in promoting the degradative changes associated with apoptosis and are divided into two classes based on the lengths of their N-terminal prodomains, including upstream caspases such as caspase- 8 and -10 and downstream caspases such as caspase-3, -6 and -9 (33). In general, caspase activation is believed to be involved in apoptosis. In the present study, western blot analysis and RT-PCR showed that caspase-9 and active-caspase-3 expression was significantly upregulated in oridonin-treated SW1990 cells. However, the high levels of caspase- 9 and -3 were also correspondingly suppressed by SB203580. These results indicated that $\mathrm{p} 38$ was responsible for causing the activation of caspase- 9 and -3 , which executed the oridonin-induced SW1990 apoptosis.

Collectively, the present study suggests that the MAPKp38 pathway was selectively activated in SW1990 pancreatic cancer cells following treatment with oridonin, and the induction of apoptosis was dependent on p53 and caspase activation. However, certain molecular links remain to be clarified, such as whether p53 is linked to caspase, and how p38 signaling acts on the caspase pathway. The specific mechanisms involved require further study. Based on these results, further clinical studies are necessary to confirm our findings in patients with pancreatic cancer.

\section{Acknowledgements}

We are grateful for the financial support from the Administration of Traditional Chinese Medicine of Zhejiang, China (grant no. 2013ZQ026) and The National Natural Science Foundation of China (grant no. 63412018).

\section{References}

1. Jemal A, Siegel R, Ward E, et al: Cancer statistics. CA Cancer J Clin 59: 225-249, 2009.

2. Löhr M: Is it possible to survive pancreatic cancer? Nat Clin Pract Gastroenterol Hepatol 3: 236-237, 2006.

3. Omura $\mathrm{N}$ and Goggins M: Epigenetics and epigenetic alterations in pancreatic cancer. Int J Clin Exp Pathol 2: 310-326, 2009.

4. Tan W, Lu J, Huang M, et al: Anti-cancer natural products isolated from Chinese medicinal herbs. Chin Med 6: 27, 2011.

5. Gao $\mathrm{FH}, \mathrm{Hu} \mathrm{XH}, \mathrm{Li} \mathrm{W}$, et al: Oridonin induces apoptosis and senescence in colorectal cancer cells by increasing histone hyperacetylation and regulation of p16, p21, p27 and c-myc. BMC Cancer 10: 610, 2010.

6. Cheng Y, Qiu F, Ye YC, Tashiro S, Onodera S and Ikejima T: Oridonin induces $\mathrm{G} 2 / \mathrm{M}$ arrest and apoptosis via activating ERK-p53 apoptotic pathway and inhibiting PTK-RAS-RAF-JNK survival pathway in murine fibrosarcoma L929 cells. Arch Biochem Biophys 490: 70-75, 2009.

7. Huang J, Wu L, Tashiro S, Onodera S and Ikejima T: Reactive oxygen species mediate oridonin-induced HepG2 apoptosis through p53, MAPK, and mitochondrial signaling pathways. J Pharmacol Sci 107: 370-379, 2008.

8. Jin S, Shen JN, Wang J, Huang G and Zhou JG: Oridonin induced apoptosis through AKT and MAPKS signaling pathways in human osteosarcoma cells. Cancer Biol Ther 6: 261-268, 2007.

9. Li D, Wu LJ, Tashiro S, Onodera S and Ikejima T: Oridonin induced A431 cell apoptosis partially through blockage of the RAS/RAF/ ERK signal pathway. J Pharmacol Sci 103: 56-66, 2007.
10. Hu HZ, Yang YB, Xu XD, et al: Oridonin induces apoptosis via $\mathrm{PI} 3 \mathrm{~K} / \mathrm{Akt}$ pathway in cervical carcinoma HeLa cell line. Acta Pharmacol Sin 28: 1819-1826, 2007.

11. Liu YQ, Mu ZQ, You S, et al: Fas/FasL signaling allows extracelluar-signal regulated kinase to regulate cytochrome $\mathrm{c}$ release in oridonin-induced apoptotic U937 cells. Biol Pharm Bull 29: 1873-1879, 2006.

12. Hsieh TC, Wijeratne EK, Liang JY, Gunatilaka AL and Wu JM: Differential control of growth, cell cycle progression, and expression of NF-kappaB in human breast cancer cells MCF-7, MCF-10A, and MDA-MB-231 by ponicidin and oridonin, diterpenoids from the Chinese herb Rabdosia rubescens. Biochem Biophys Res Commun 337: 224-231, 2005.

13. Ikezoe T, Chen SS, Tong XJ, et al: Oridonin induces growth inhibition and apoptosis of a variety of human cancer cells. Int J Oncol 23: 1187-1193, 2003.

14. Bunz F, Dutriaux A, Lengauer C, et al: Requirement for p53 and $\mathrm{p} 21$ to sustain G2 arrest after DNA damage. Science 282: 1497-1501, 1998.

15. Perfettini JL, Castedo M, Nardacci R, et al: Essential role of p53 phosphorylation by p38 MAPK in apoptosis induction by the HIV-1 envelope. J Exp Med 201: 279-289, 2005.

16. Kuribayashi K and El-Deiry WS: Regulation of programmed cell death by the p53 pathway. Adv Exp Med Biol 615: 201-221, 2008.

17. Fuster JJ, Sanz-González SM, Moll UM and Andrés V: Classic and novel roles of p53: prospects for anticancer therapy. Trends Mol Med 13: 192-199, 2007.

18. Burns TF, Fei P, Scata KA, et al: Silencing of the novel p53 target gene Snk/Plk2 leads to mitotic catastrophe in paclitaxel (taxol)exposed cells. Mol Cell Biol 23: 5556-5571, 2003.

19. Vousden KH and Lane DP: p53 in health and disease. Nat Rev Mol Cell Biol 8: 275-283, 2007.

20. Shankar S, Singh G and Srivastava RK: Chemoprevention by resveratrol: molecular mechanisms and therapeutic potential. Front Biosci 12: 4839-4854, 2007.

21. Lee JT, Lehmann BD, Terrian DM, et al: Targeting prostate cancer based on signal transduction and cell cycle pathways. Cell Cycle 7: 1745-1762, 2008.

22. McCubrey JA, LaHair MM and Franklin RA: Reactive oxygen species-induced activation of the MAP kinase signaling pathways. Antioxid Redox Signal 8: 1775-1789, 2006.

23. Kholodenko BN and Birtwistle MR: Four-dimensional dynamics of MAPK information processing systems. Wiley Interdiscip Rev Syst Biol Med 1: 28-44, 2009.

24. Rodríguez-Berriguete G, Fraile B, Martínez-Onsurbe P, et al: MAP kinases and prostate cancer. J Signal Transduct 2012: 169170, 2012.

25. Schaeffer HJ and Weber MJ: Mitogen-activated protein kinases: specific messages from ubiquitous messengers. Mol Cell Biol 19: 2435-2444, 1999.

26. Zarubin T and Han J: Activation and signaling of the p38 MAP kinase pathway. Cell Res 15: 11-18, 2005.

27. Whyte J, Bergin O, Bianchi A, McNally S and Martin F: Key signalling nodes in mammary gland development and cancer. Mitogen-activated protein kinase signalling in experimental models of breast cancer progression and in mammary gland development. Breast Cancer Res 11: 209, 2009.

28. Royuela M, Rodríguez-Berriguete G, Fraile B and Paniagua R: TNF- $\alpha /$ IL-1/NF- $\kappa$ B transduction pathway in human cancer prostate. Histol Histopathol 23: 1279-1290, 2008

29. Thornton TM and Rincon M: Non-classical p38 map kinase functions: cell cycle checkpoints and survival. Int J Biol Sci 5: 44-51, 2009.

30. Harris SL and Levine AJ: The p53 pathway: positive and negative feedback loops. Oncogene 24: 2899-2908, 2005.

31. Wu GS: The functional interactions between the p53 and MAPK signaling pathways. Cancer Biol Ther 3: 156-161, 2004.

32. Bulavin DV and Fornace AJ Jr: p38 MAP kinase's emerging role as a tumor suppressor. Adv Cancer Res 92: 95-118, 2004.

33. Degterev A, Boyce M and Yuan J: A decade of caspases. Oncogene 22: 8543-8567, 2003. 